\title{
Feature-based generation of machining process plans for optimised parts manufacture
}

\author{
Mariusz Deja • Mieczyslaw S. Siemiatkowski
}

Received: 3 August 2011 / Accepted: 20 February 2012 / Published online: 15 March 2012

(C) The Author(s) 2012. This article is published with open access at Springerlink.com

\begin{abstract}
Efficacious integration of such CAx technologies as CAD, CAM and CAPP still remains a problem in engineering practice which constantly attracts research attention. Design by feature model is assumed as a main factor in the integration effort in various engineering and manufacturing domains. It refers principally to feature clustering and consequently operation sequencing in elaborated process plan designs. The focus of this paper is on CAPP for parts manufacture in systems of definite processing capabilities, involving multi-axis machining centres. A methodical approach is proposed to optimally solve for process planning problems, which consists in the identification of process alternatives and sequencing adequate working steps. The approach involves the use of the branch and bound concept from the field of artificial intelligence. A conceptual scheme for generation of alternative process plans in the form of a network is developed. It is based on part design data modelling in terms of machining features. A relevant algorithm is proposed for creating such a network and searching for the optimal process plan solution from the viewpoint of its operational performance, under formulated process constraints. The feasibility of the approach and the algorithm are illustrated by a numerical case with regard to a real application and diverse machine tools with relevant tooling. Generated process alternatives for complex machining with given systems, are studied using models programmed in the environment of Matlab ${ }^{\circledR}$ software.
\end{abstract}

\section{Deja (西) · M. S. Siemiatkowski}

Department of Manufacturing Engineering and Automation,

Mechanical Engineering Faculty, Gdansk University of Technology,

11/12 Narutowicza Str., 80-233 Gdansk, Poland

e-mail: mdeja@pg.gda.pl

M. S. Siemiatkowski

e-mail:msiemiat@pg.gda.pl
Keywords Process plan selection - CAPP - Generative methods - Optimal design · Machining features - Dynamic programming

\section{Introduction}

Contemporary manufacturing is realised in the face of tough global competition, under demand on high productivity and product quality, large-variety customised production and increasing attention being paid to shortening product development life cycles (Molina et al. 2005; Zheng et al. 2008). For the last two decades CAD/CAM technologies have been extensively developed to automate and integrate individual activities in the design and manufacturing cycle. Moreover, computer-aided process planning (CAPP) as a momentous task in product development cycle, has particularly attracted a lot of research interest (Kang et al. 2003; Mokhtar and Xu 2011). The task involves interpretation and conversion of design specifications to appropriate data required for product manufacture. In this regard, the use of a feature-based data model has been considered as the adequate technology for interlinking the engineering domains and disparate computer systems. The application of feature-based process planning has gained ground recently in supporting the efficient CAD and CAM integration (Gao et al. 2004; Zhou et al. 2007). Features are assumed inherently as a main factor in such an integration effort because of the association of various design, engineering and manufacturing data used by CAPP (Liu and Wang 2007; Tanaka and Kishinami 1998; Wang et al. 2006). Proper sequencing of machining features still remains a challenging issue in CAPP due to its complexity and adherence to the class of nondeterministic polynomial-time problems (Mokhtar and Xu 2011). Its direct influence on machining efficiency and part quality has also been widely recognised. 
The prior acquisition of precedence information between features becomes a key task in a CAPP system which gives the possibility for generating an effective and reliable operation sequence in part machining. More importantly, determining machining precedence of features becomes even more difficult in case of geometric interactions occurring among them that usually lead to alternative sets of machining sequences. It is worth also noticing that other corresponding activities within process planning stage such as tooling selection, fixture design, setup planning, etc. can be chained with definite sets of features during feature sequencing. In such a case some kind of feature recognition from a given 3-D model of a part component is needed to automate the generation of setup plans in CAPP systems. According to numerous reports however, and among those of Kang et al. (2003); Rameshbabu and Shunmugam (2009) or Zhou et al. (2007), there are substantial difficulties in regards to proper integration of feature recognition concepts and downstream applications like setup planning, etc.

Despite the efforts done so far, as reported by e.g. Hayasi and Asiabanpour (2009), and also by Zhou et al. (2007), sharing manufacturing information within a product development lifecycle still remains a bottleneck. As implied earlier in Sormaz and Khoshnevis (2003) a common deficiency of most often reported CAPP systems is that they act as standalone function and generally in a batch mode, excluding the possibility for real-time integration with $\mathrm{CAD}, \mathrm{CAM}$ or production scheduling modules. Consequently, these systems are not suitable to incorporate any changes in product design for incremental process plan generation.

To cope with the new, and aforementioned, market challenges related to manufacturing area in a cost-effective manner advancing flexible manufacturing systems (FMSs) technology has been implemented. The extended use of multi-axis machining centres has become the noticeable tendency in manufacturing practice of recent years, and mostly due to their capability of performing different types of operations on multiple planes of a work piece for any given setup (Molina et al. 2005). This is also apparently consistent with the aim after complete machining (operation concentration), i.e. machining the entire part in a single setup in a definite machine tool. The efficient application of those manufacturing means is decided by utilisation level of their machining components, such as: multiple spindles, turrets, indexing tables, additional tooling and fixtures. Mostly, as reported e.g. in the paper by Chung and Suh (2008), a limited range of the machine tools capabilities is used at any given instant. Consequently, reconfigurable machines and their systems, which can provide only the flexibility needed to produce a specific parts spectrum and to avoid unused capacity of multiaxis work centres, have gained ground instead. Great operational potential of those general purpose machine tools is not fully utilised in industry, mainly due to the imperfections of applied process planning methods. This may be referred to both technologies of manual planning assumed by skilled operators and those accomplished in an automated manner using dedicated commercial CAPP systems.

The availability of alternative process plans is pointed out as a key factor in integration of design, process planning, and scheduling functions. Offering several process plan solutions for diverse machined components, may be helpful in the relaxation of the constraints in the optimisation of production schedules and process control. This in turn may yield more efficient utilisation of machine resources, correspondingly to reductions in manufacturing cycle times (Sormaz and Khoshnevis 2003; Chung and Suh 2008).

This research paper deals with issues related to planning alternative process solutions in the environment of integrated machining systems of extended and definite processing capabilities. The issues are considered under the requirements for agile manufacturing. A conceptual scheme for generation of process plan alternatives in the form of a network is developed, based on part design data modelling by machining features. A relevant algorithm is proposed for creating such a network and searching for the optimal process plan solution in terms of standardised operational performance criteria and under formulated process constraints.

\section{Overview of related research work}

The subjects of computer-aided process planning have generally attracted a great deal of research attention and there exists an abundant amount of literature on this topic. The most recent survey of CAPP research works was written by Xu et al. (2011). In their up-to-date and comprehensive review, the authors attempt to ascertain the current status of CAPP and anticipate future trends in this area, covering the related technologies developed for machining since the late 1990s but mostly after 2000. Discussions concerning the recent CAPP research are presented in a number of distinguished categories, including: feature-based technologies, knowledge-based systems, artificial neural networks, genetic algorithms, fuzzy set theory and fuzzy logic, Petri nets, agent-based technology, Internet-based technology and STEP-compliant CAPP. The paper also includes a respective summary of previous surveys published by other authors, and more importantly the relevant analysis of some emerging technologies, either developed or adapted for supporting adequate process planning tasks. A significant and integral part of the review provided is the discussion of some topical CAPP related issues, and among others: tool selection, setup planning, operation selection and sequencing, decision models, integration of process planning with production system as well as non-linear process planning. Apart from those mentioned, the relevant efforts and available possibilities for 
commercialisation of CAPP research are outlined and the need for closer cooperation between CAPP researchers and the industry are strongly recommended.

Studying existing literature suggests that despite significant progress, particularly the issues related to system integration of CAD and CAPP still remain to be fully solved. Much of current research effort is devoted to features recognition that plays an important role in the integration of CAD, CAM and CAPP. This includes papers of Gao et al. (2004) as well as Hayasi and Asiabanpour (2009), respectively, who proposed adequate system approaches, using the rule-based methods and special algorithms to recognize the variety of non-intersecting features and to convert them into machining features. The determination of proper machining precedence becomes more difficult when features being considered interact with each other, as clearly shown in Mokhtar and Xu (2011). Lee et al. (2007) in turn presented a scheme for composite feature recognition with automatic process planning, involving precedence relations among features derived from CAD data model and based on a topological sorting.

STEP-NC data structure is utilised as the feature-based product model by Mokhtar et al. (2009) so as to generate the precedence information for interacting machining features, under consideration of roughing and finishing operations for those features. A hybrid feature recognition method, based on volume subtraction and face adjacency graph, is in turn proposed by Rameshbabu and Shunmugam (2009). It is shown as the mean capable of recognising intersecting manufacturing features with relative ease using 3D model data recorded in the STEP AP-203 format. The integration of design and manufacturing specific tasks based on STEP standard is discussed in more detail by Zhao et al. (2009).

A considerable part of related research work on feature-based process planning deals with issues of sequencing machining operations and setup planning. Existing approaches, and among others those developed by Rameshbabu and Shunmugam (2009); Sormaz and Khoshnevis (2000) or Wong et al. (2003) aimed at solving the issues are based on diverse decision criteria, considering setup and tool changes, tool access direction, operation time, etc. Mokhtar and Xu (2011) in particular, suggest the need for sequencing machining operations based on two types of classified constraints: machining operation specific constraint and part geometry - related precedence constraint. An automatic setup planning module for machining of prismatic parts was developed by Gologlu (2004). Machining and fixturing constraints are considered simultaneously by the CAPP system prototype to ensure the effective generation of process plans. At the same time, the best datum surfaces for supporting, locating and clamping the part can be identified.

One of the rules for the assignment of features to setups is the consideration of tool approach directions (TAD) as presented, among others, in research papers of Gologlu
(2004) or Liu and Wang (2007). As indicated in these papers, features with the same TAD can be grouped into feature clusters and machined within one setup. The objective of this planning strategy is to reduce the number of setups as well as part machining time by sequencing of features within one setup that might reduce the number of required tool changes. Similarly, Park (2003) implies the possibility for the aggregation of machining operations with the reference to unit volume decomposition for complex features. Apart from the geometric reasoning rules, just Liu and Wang (2007) proposed the use of more detailed knowledge-based rules for determining machining precedence constraints, with regard to the sequence between setups and also to feature sequencing within each consecutive setup. Wang and Shen (2003) advocate a decentralization in CAPP system architecture and develop a novel method of distributed process planning (DPP) characterized by increased system responsiveness, correspondingly with the requirements of dynamic, reconfigurable and distributed manufacturing environments. An agent-based approach is adopted for intelligent (adaptive) decision-making in process planning area. The integration of feature-based process planning and function block (FB)-based process execution with the agent-based decision making is at the core of the proposed method. Unlike the traditional methods, the proposed approach utilises a two-level decision-making strategy, i.e. supervisory planning and operation planning. Consequently, the proposed DPP separates generic and machine-specific information of process plans by assigning operation planning tasks to open-architecture CNC controllers. In order to realise the concept of DPP, Wang et al. (2006) propose a reasoning approach to generic machining process sequencing, based on enriched machining features (EMFs). An EMF is represented by combining its machining volume with surface, geometric and volume features, as well as other technological information needed to machine the feature. Machine-neutral process plans of a given part are generated on the basis of manufacturing constraints and datum references. The grouping of EMFs include three steps: choosing datum references, finding a primary locating direction and creating appropriate set-ups.

In most CAPP-related publications, geometric interactions between features, the data sets concerning dimensions and tolerances are used for sequencing features within each individual setup, as assumed in the design schemes of Gologlu (2004), and also Liu and Wang (2007). The problem of embedding, in current CAD models, non-geometric technological information, such as dimensional and geometric tolerance, surface roughness and hardness, that is necessary for CAPP, is also discussed by Zhou et al. (2007). In process design for the conditions of current manufacturing practice, decision making frequently involves dealing with uncertain and imprecise information. An adequate fuzzy approach for solving the process plan selection and operation sequencing 
under uncertainty is described in the research work of Wong et al. (2003). The factors of uncertainty are also taken into account by Wang et al. (2010), who develop an adaptive setup planning (ASP) approach that is suitable for the conditions of dynamic system operation. It envisages both availability and capability of machines on a shop floor since setup plans generated in advance are often subject to changes even before their executions.

Sormaz and Khoshnevis (2003), and later Zheng et al. (2008) reported on their relevant approaches for generating alternative process plans in the form of a process plan network along with the algorithms for their optimization. In both approaches, the selection of the process plan to be used for parts manufacture is based on the minimization of time and/or cost. The availability of alternative process plans provides the required flexibility to select different process plans, depending on the current status of required resources in a manufacturing shop floor.

The possibility for generation of alternative setups as the part of process planning procedure is also widely studied by Raman and Marefat (2004). In the presented solution the setups and adequate tool sets are assigned to each of the features with the objective of minimizing the total machining cost. Minimizing the setup cost, gained by minimising the number of setups, is an important factor in minimising total machining cost due to expensive fixturing procedure.

Some of the features can be additionally restricted in terms of machining due to machine-fixture relationships as noted in the publication of Gologlu (2004). Alternatives of fixture elements and machines are represented in this paper by alternative machining systems. Choosing particular machining systems results in the feature sequencing, since some of the features can not be machined until so called fixturing features, required for the chosen system, are completed.

The literature survey confirms the authors' belief that the availability of process alternatives could be useful from the viewpoint of an adaptive process planning in dynamically changing manufacturing environments.

\section{Modelling framework in process plan decision-making}

Process planning activities basically involve the process selection, operation sequencing and the allocation of adequate machining equipment according to part design specification and the manufacturing conditions. Using the quantitative approach the process selection and sequencing problem is formulated as the minimization of an objective function and mostly of total manufacturing time and/or cost subject to definite constraints, as it is assumed by Chung and Suh (2008) as well as Sormaz and Khoshnevis (2003). Thereby, process planning function can be realised by a two-stage procedure comprising: intra- and inter-feature planning (Wong et al. 2003), also termed as micro- and macro planning by such authors as: Mokhtar et al. (2009); Srinivasan and Sheng (1999) or Zhao et al. (2009). The local optimum operation sequence is first established for each feature, and then the optimal global sequence is generated for the complete set of features (Mokhtar et al. 2009). Considering its combinatorial nature, the optimisation problem can be solved using the branch-and-bound (BB) approach and heuristics derived from engineering insights into process sequencing and scheduling for complex machining on multi-axis centres.

\section{Data model for CAPP}

The scheme developed for the generation of process alternatives for parts manufacture assumes the input data model based on two interrelated information sets, and describing a feature itself and the feature precedence relationships, respectively. Reconstruction of a feature precedence tree along with the technological information processing is indicated as crucial to total integration of CAD and CAPP systems (Gao et al. 2004; Zhou et al. 2007). As reported recently, also some dedicated systems using fuzzy logic and genetic approaches in solving the operation sequencing problem are designed to link up with a feature-based design or feature recognition system to obtain complete part design data (Wong et al. 2003).

One of the knowledge-based rules proposed by Liu and Wang (2007) is the dominant role of the setup $A$ with the precedence feature of another feature in setup $B$. This kind of the rule can be also applied for feature sequencing within one setup. Machining the precedence features first may lead to the number of setups reduction by opening more possible alternatives. Features having multiple occurrences, in different setups, are retained with clusters having maximum number of features, similarly as given in Rameshbabu and Shunmugam (2009).

Thus, the framework assumes that relevant subsets of features types (pattern features) of definite requirements related to definite typologies of geometric entities are represented in the knowledge base to be utilised in creating diverse process instances.

The feature precedence relationships in turn are coded within the following feature precedence matrix FPM = $\left[f_{i j}\right]_{i \leq m, j \leq n}$, where: $m$ - the maximum number of required preceding features for a specific feature, $n$-the total number of features, and $f_{i j}<n$. The value of a single element of FPM matrix $f_{i j}$ is strictly correlated with the location of the corresponding feature $\# j$ on the feature precedence tree. The numerical value 0 is assigned to the all initial features (of the highest level), in the first row of the FPM matrix. The child features are given then the values correspondingly to the numbers of directly preceding features. Hence, if the feature $\# u$ needs the feature $\# v$ to be completed, the value 
of $f_{1, u}=v$; and if the feature \#u has more than one parent, e.g. the features: $\# v$ and $\# w$, two elements: $f_{1, u}=v$, and $f_{2, u}=w$ occur in the column $\# u$. The value of -1 for $f_{i j}$ with $1<i \leq m, j \leq n$, indicates no other relationships apart from those coded in the first row $(i=1)$.

The processing alternatives for individual part features are recorded in the form of the binary process capability matrix $\mathbf{P C M}=\left[p_{i j}\right]_{i \leq k, j \leq n}$, where: $k$-the number of available machining systems, $n$ - the total number of discerned features. Single machining system $\# i$ is understood as the combination of a machine tool and assigned fixture type. This is assumed consistently with the approach of Gologlu (2004) who represented the interactions between the fixture elements and the work piece by machine-fixture relationships. Apparently, due to these interactions some of the features might be inaccessible to machining. Sets of fixture elements and machines are represented as alternative machining systems \#i. Some of the features, called fixturing features, are required to be machined first, depending on the chosen set. These types of features, which have already been machined or are identified from unmachined feature are the locating surfaces. Some of the fixturing concepts can not be used if specific fixturing features have not been machined. According to Rameshbabu and Shunmugam (2009), the feature cluster with larger number of features is preferred to be machined last as it affects locating and clamping in subsequent setups. Just the opposite, in our approach, machining this feature cluster is suggested as first. This extends possibilities for part fixturing in consecutive operations since more fixturing and opening features can be machined.

To ensure the feasibility of generated process plan candidates the operation precedence conditions have to be determined. This may be referred to the necessity of prior machining the datum feature in one of alternative systems to continue the machining process in a system with specific fixture type using this datum. Consequently, these limitations are defined in the unique constraints matrix for the availability of machining systems, and formulated as: $\mathbf{C M}=\left[c_{i j}\right]_{i \leq h, j \leq k}$, where: $h$-the maximum number of required preceding machining systems for a given machining system, $k$ - the total number of machining systems and $c_{i j}<k$. The value of a single element of the matrix $c_{i j}$ expresses the precedence of machining systems. The systems available at any stage of a manufacturing process are given the value 0 in the first row of the $\mathbf{C M}$ matrix. For the system $\# u$ requiring the use of the system $\# v$ in the previous setup, the value of $c_{1, u}=v$; and if there are more systems which can be applied interchangeably before the system $\# u$, e.g. the system $\# v$ or the system $\# w$, two elements: $c_{1, u}=v$, and $c_{2, u}=w$ occur in the column \#u. The value of -1 for $c_{i j}$, with $1<i \leq h, j \leq k$, indicates no other constraints apart from those coded in the first row.
A substantial part of the input data model are also the machining time matrix $\mathbf{M T M}=\left[t_{i j}\right]_{i \leq k, j \leq n}$, and the setup time matrix $\mathbf{S T M}=\left[\mathrm{s}_{i}\right]_{i \leq k}$. Those matrices are directly used in quantitative evaluation of generated setup sequences and the overall process plan alternatives under consideration. Thus, the entries of the former matrix include the time values concerning machining individual features within definite systems. With regard to the latter matrix, its entries involve the changeover times of individual systems associated with accomplishing the subsequent process tasks. The machining process operation times are considered deterministic all over the research, since $\mathrm{NC}$ part programs dictate in full the actual cutting time. Apparently, the same assumption can be referred to the other manufacturing time components.

\section{Process selection and operation sequencing}

Considering the assumptions made with regard to information data model, the overall hierarchical structure of the system under development is depicted in Fig. 1. Three stages are discerned in the system structure: the intra-feature planning and the inter-feature planning that is followed by quantitative assessment of determined operation sequences in process plan alternatives. At the former stage of the system structure geometric entities of part components are identified as machining features together with technological requirements related to them. This stage is integrated with the CAD solid modelling environment and the analysis of occurring feature interactions. As a result, the appropriate processes are selected for each feature in a knowledge-based fashion, after comparing their capabilities and the feature requirements. At a time, priority relations are introduced to diminish the number of possible process alternatives for single features. The machine tools with relevant tooling and tool sets are then specified and next cutting parameters are selected for each generated process instance. The last phase of this stage involves the estimation of relevant feature machining time components and related cost. The macro-planning stage of the structure is meant for clustering and sequencing of machining operations for sets of interrelated features, with the aim to optimise the overall process plan. Data analysed in feature clustering module are written numerically in three matrixes described in the previous section and presented in the block diagram of proposed set-up planning module. Thus, geometric and process based interactions among features, resulting from tool and setup changes, are analysed in detail. At the final stage, all feasible alternatives are generated and then extracted with the use of the developed decision scheme. Those alternatives are mapped in the form of hierarchical process decision trees and as a result, the optimal process plan is found. The respective analysis involves the calculation of manufacturing times considering the possibilities for operation concentration and its differentiation. The analysis 
Fig. 1 Outline of the system solution for optimal process plan selection based on proposed feature clustering module

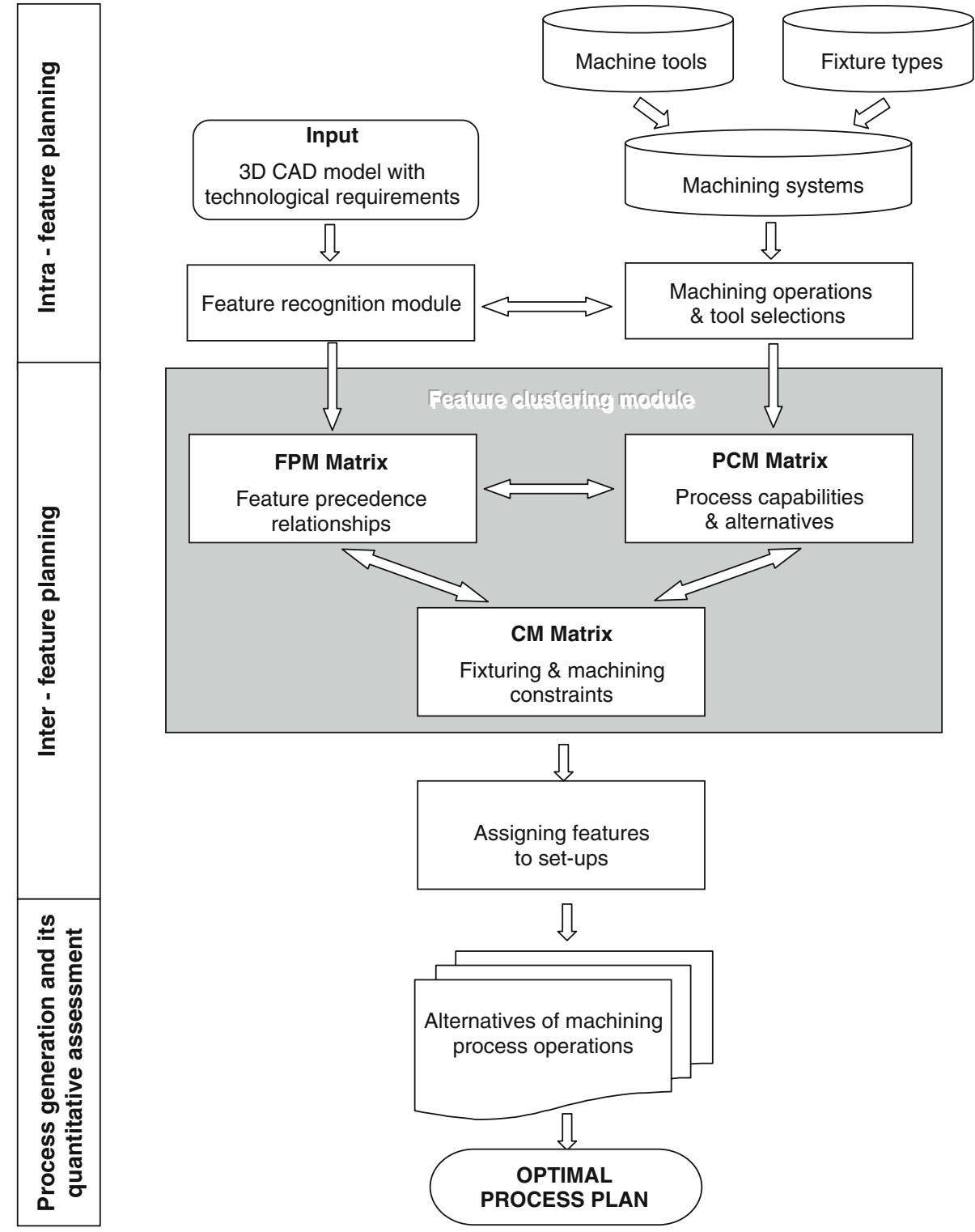

includes the considerations of such part manufacturing time components, as: machining time per unit, part handling time, tool change time as well as changeover and setup times, etc.

The approach proposed to generate a set of process alternatives under the interchange ability of machining systems and then to identify the optimal or near-optimal process plan solution is summarised in Table 1. The procedure starts with the selection of features, assigned to the highest level in the feature precedence tree, initiating process and the first setupstep 1. Machining systems, in which maximum number of related features can be accomplished, are identified with the use of PCM and $\mathbf{C M}$ matrices-steps $2 \div 4$. Subsequent features are identified in the similar manner in steps $5 \div 8$. After the setup completion, the machining time is calculated and alternatives with minimum time are chosen-step 9. The alternative is eliminated in step 10 if it is evident that it will not approach the benchmark value in the current or in the next setup. The promising alternatives are analysed in further setups-step 11. The process alternative of minimum cycle time is set as a benchmark in step 13 after computing total manufacturing time for all alternatives under consideration (step 12). Other alternatives are searched in the backward reasoning mode with the consideration of the reminder of existing machining capabilities-step 14. Finally, the optimal process plan solution is generated-step 15 .

\section{Illustrative case study}

The efficacy and usability of the proposed approach is tested with regard to manufacture of mechanical parts in the SIM plant, which is aimed at small batch production of 
Table 1 Detailed heuristic procedure for process selection and operation sequencing

\begin{tabular}{|c|c|}
\hline Step \# & Algorithm/procedure description \\
\hline Input data & $\begin{array}{l}\mathbf{F P M}=\left[f_{i j}\right], \mathbf{P C M}=\left[p_{i j}\right], \mathbf{C M}=\left[c_{i j}\right], \mathbf{M T M}=\left[t_{i j}\right], \mathbf{S T M}=\left[s_{i}\right] \\
\left.\text { Additional matrices used for calculations: } \mathbf{I}_{\mathbf{f}}=[], \mathrm{I}_{\mathbf{p}}^{*}=[], \text { threshold B [time units }\right]\end{array}$ \\
\hline 1 & $\begin{array}{l}\text { Selection of features initiating a process or a setup, available for machining based on FPM matrix } \\
\text { In the first row of } \mathbf{F P M}=\left[f_{1 j}\right]_{j \leq n} \text {, find } j \text { (the number of column) for which } f_{1 j}=0 \text { and generate the vector } \\
\mathbf{J}_{\mathbf{s}}=\left[j_{s}\right]_{s \leq j 0} \text {, where } j_{0}-\text { number of initiating features. } \\
\text { Use } \mathbf{I}_{\mathbf{f}}=[i f] \text { and find more } j \text { in } \mathbf{F P M}=\left[f_{i j}\right] \text { for which all } f_{i j}=\text { any } i_{f} \text { or }-1 \text {, and next including all } j \\
\text { generate the vector } \mathbf{J}_{\mathbf{q}}=\left[j_{q}\right]_{q<n}\end{array}$ \\
\hline 2 & $\begin{array}{l}\text { Checking process capabilities for selected features using PCM matrix } \\
\text { For selected columns written in } \mathbf{J}_{\mathbf{q}} \text {, find } i \text { in the matrix } \mathbf{P C M}=\left[p_{i j}\right]_{i \leq k, j=\mathbf{J q}} \text {, where any } p_{i j}=1 \text { and generate } \\
\text { the new vector of available machining systems, } \mathbf{I}_{\mathbf{r}}=\left[i_{r}\right]_{r<k}\end{array}$ \\
\hline 3 & $\begin{array}{l}\text { Inclusion of corresponding machining system(s) by CM matrix into possible processing alternatives under consideration } \\
\text { In the first row of } \mathbf{C M}=\left[c_{1 j}\right]_{j \leq k} \text {, find } j \text { for which } c_{1 j}=0 \text { and next generate the vector of available machining } \\
\text { systems } \mathbf{J}_{\mathbf{r}}=\left[j_{r}\right]_{r \leq k} \text {. Using } \mathbf{I}_{\mathbf{p}}^{*}=\left[i_{p}^{*}\right] \text { (elements of } \mathbf{I}_{\mathbf{p}}^{*} \text { are generated at the Step \#10, initially } \mathbf{I}_{\mathbf{p}}^{*}=[] \text { ), find } \\
\text { more } j \text { in } \mathbf{C M} \text { for which any } c_{i j}=\mathbf{a n y} i_{p}^{*} \text { and add it to } \mathbf{J}_{\mathbf{r}} \text {. }\end{array}$ \\
\hline 4 & $\begin{array}{l}\text { Identification of the machining system(s) with maximum number of related features, initiating a process or a setup } \\
\text { For selected rows and columns written in } \mathbf{J}_{\mathbf{r}} \text { and } \mathbf{J}_{\mathbf{q}} \text {, respectively, find } i \text { in the matrix } \mathbf{P C M}=\left[p_{i j}\right]_{i \in \mathbf{J r}, j \in \mathbf{J q}} \text {, } \\
\text { with } \sum p_{i}=\max \text { and record results: } i \text { in } \mathbf{I}_{\mathbf{p}}=\left[i_{p}\right]_{p \leq r} \text { for machining systems and } j \text { in } \mathbf{I}_{\mathbf{f}}=\left[i_{f}\right]_{f \leq n} \text { for } \\
\text { features. Update } \mathbf{I}_{\mathbf{f}} \text { including the consecutive subset(s) of features. }\end{array}$ \\
\hline 5 & $\begin{array}{l}\text { Selection of subsequent features available for machining based on FPM matrix, if any; otherwise go to Step } 9 \\
\text { Replace entries of } \mathbf{F P M} \text { with value }-2 \text { for columns given in } \mathbf{I}_{\mathbf{f}} \text { to exclude machined features. Using } \mathbf{I}_{\mathbf{f}}=\left[i_{f}\right] \text {, } \\
\text { find } j \text { in } \mathbf{F P M}=\left[f_{i j}\right] \text { for which all } f_{i j}=\text { any } i_{f} \text { or }-1 \text {; for found } j \text { generate a new vector } \mathbf{J}_{\mathbf{q}}=\left[j_{q}\right]_{q \leq n} \text {; if } \\
\mathbf{J}_{\mathbf{q}}=[] \text { go to Step } 9 \text {. }\end{array}$ \\
\hline 6 & $\begin{array}{l}\text { Checking process capabilities for the selected features and extracted machining system(s) using PCM matrix; if } \\
\text { the need for setup (machining system change) is encountered go to Step } 9 \\
\text { For selected rows and columns written in } \mathbf{I}_{\mathbf{p}} \text { and } \mathbf{J}_{\mathbf{q}} \text {, respectively, find } i \text { in the matrix } \mathbf{P C M}=\left[p_{i j}\right]_{i \in \mathbf{I p}, j \in \mathbf{J q}} \text {, } \\
\text { where } p_{i j}=1 \text { and update } \mathbf{J}_{\mathbf{r}}=\left[j_{r}\right]_{r \leq k} \text { with still considered machining systems, if } \mathbf{J}_{\mathbf{r}}=[] \text { go to Step } 9\end{array}$ \\
\hline 7 & $\begin{array}{l}\text { Identification of the machining system }(s) \text { with maximum number of features in the subset(s) } \\
\text { For selected rows and columns written in updated } \mathbf{J}_{\mathbf{r}} \text { and } \mathbf{J}_{\mathbf{q}} \text {, respectively, find } i \text { in the matrix } \\
\mathbf{P C M}=\left[p_{i j}\right]_{i \in \mathbf{J r}}, j \in \mathbf{J q} \text {, with } \sum_{i} p_{i}=\max \text { and record results in a new } \mathbf{I}_{\mathbf{p}}=\left[i_{p}\right]_{p \leq r} \text { for machining system(s) } \\
\text { and update } \mathbf{I}_{\mathbf{f}}=\left[i_{f}\right]_{f \leq n} \text { including the consecutive subset(s) of features }\end{array}$ \\
\hline 8 & Go to Step 5 \\
\hline 9 & 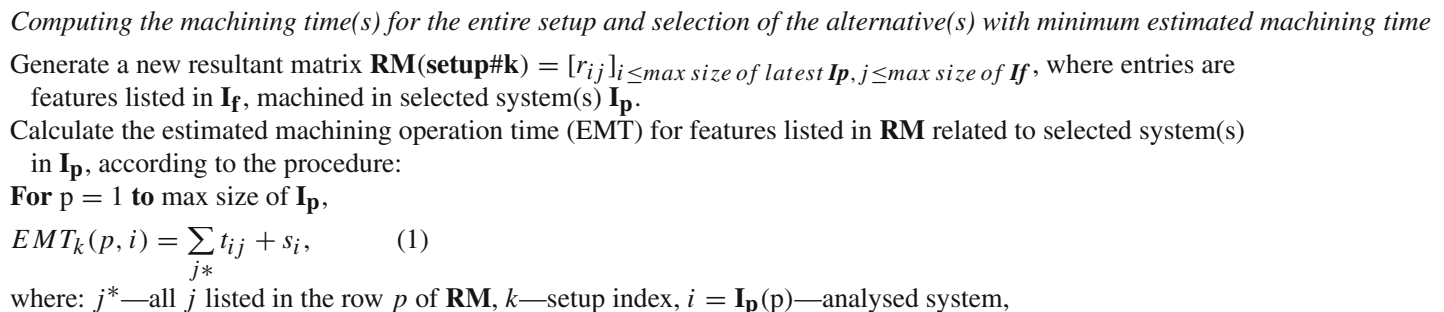 \\
\hline
\end{tabular}

End.

Select a system \#i with minimum $E M T_{k}$.

Calculating machining time for finished setup $(s)$ in related process alternatives and comparing its value to the assumed benchmark (initially set as a threshold value of B [time units]).

Append $\mathbf{I}_{\mathbf{p}}^{*}$ of chosen machining systems which could be required by other systems.

Sum up the machining operation times for alternative \# (A) found and finished setups, as:

$S M T_{A}=\sum_{k} E M T_{k}$,

If $S M T_{A} \leq \mathrm{B}$ continue, else go to Step 14 .

Return to Step 1 for machining missing feature(s) in a consecutive setup, if any.

Assuming total manufacturing time (TMT) for the alternative(s) under consideration.

$T M T_{A}=S M T_{A}$

Setting the process alternative of minimum manufacturing time as a new benchmark $B$. 


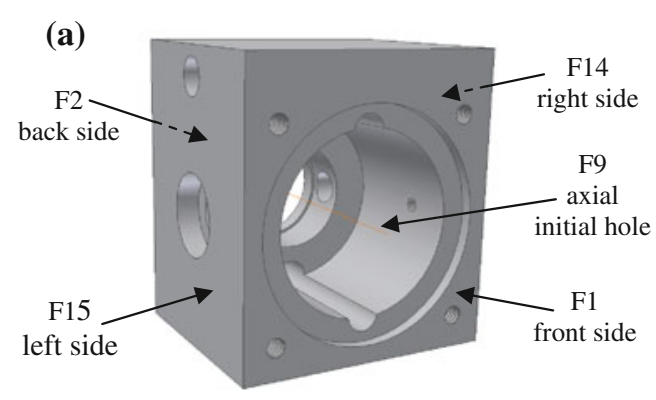

(b)

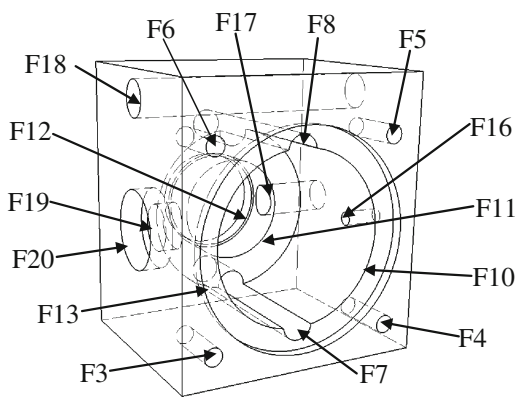

(c)

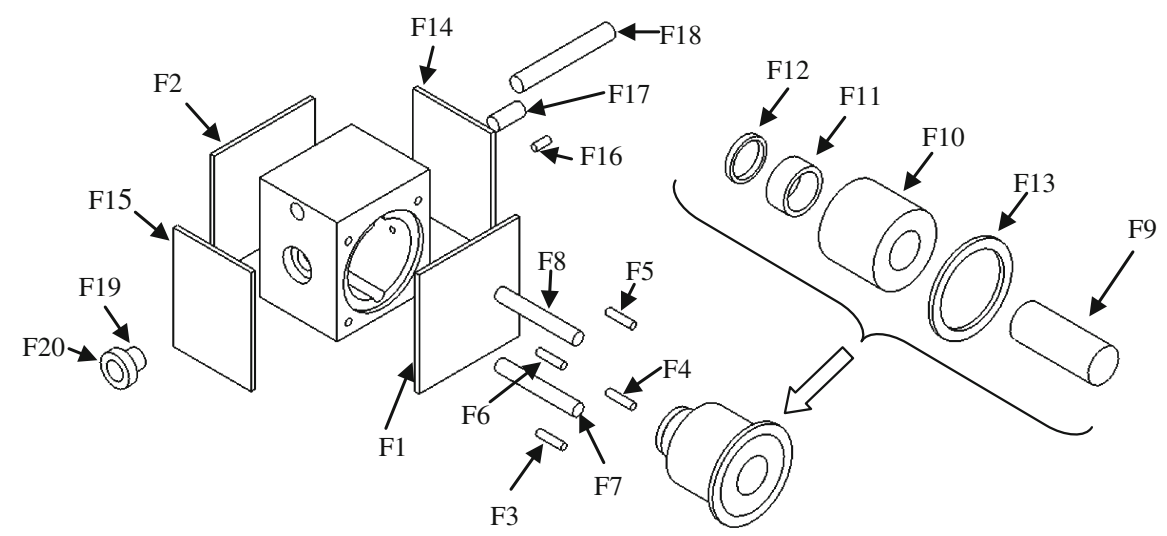

Fig. 2 The sample mechanical component with machining features: a solid model, $\mathbf{b}$ wire-frame representation, $\mathbf{c}$ discerned features in an exploded view

(a)

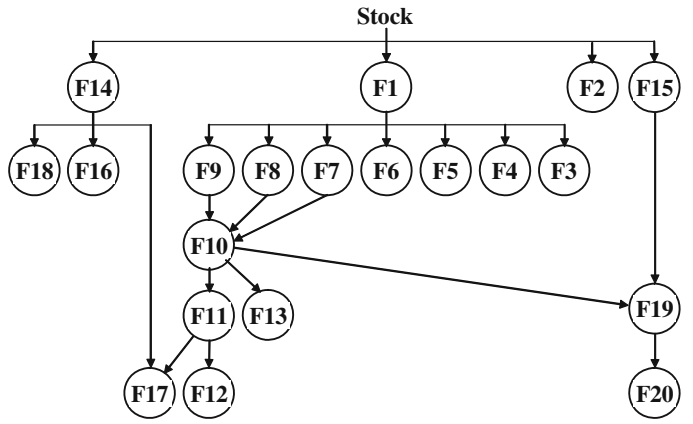

(b)

Feature \#

$\mathbf{F P M}=\left[\begin{array}{cccccccccccccccccccc}1 & 2 & 3 & 4 & 5 & 6 & 7 & 8 & 9 & 10 & 11 & 12 & 13 & 14 & 15 & 16 & 17 & 18 & 19 & 20 \\ 0 & 0 & 1 & 1 & 1 & 1 & 1 & 1 & 1 & 7 & 10 & 11 & 10 & 0 & 0 & 14 & 14 & 14 & 15 & 19 \\ -1 & -1 & -1 & -1 & -1 & -1 & -1 & -1 & -1 & 8 & -1 & -1 & -1 & -1 & -1 & -1 & 11 & -1 & 10 & -1 \\ -1 & -1 & -1 & -1 & -1 & -1 & -1 & -1 & -1 & 9 & -1 & -1 & -1 & -1 & -1 & -1 & -1 & -1 & -1 & -1\end{array}\right]$

Fig. 3 Feature precedence tree (a) and related precedence matrix (b) of the sample work piece

industrial fittings components. The sample workpiece consists of 20 machining features of definite technological requirements-Fig. 2. The feature precedence tree related to this real case example is shown in Fig. 3a. Using this descriptive means, the feature precedence relationships are coded in the FPM matrix with 20 columns and 3 rows as given in Fig. $3 b$.
The analysis of process capabilities related to the case, included the process realisation with the utilisation of horizontal- as well as vertical work centres, along with part palletising. For the simplicity, the differences in process candidates for machining features are represented just by selecting different machining systems under the consideration of both one-piece (Fig. 4) and multi-piece 
(a)

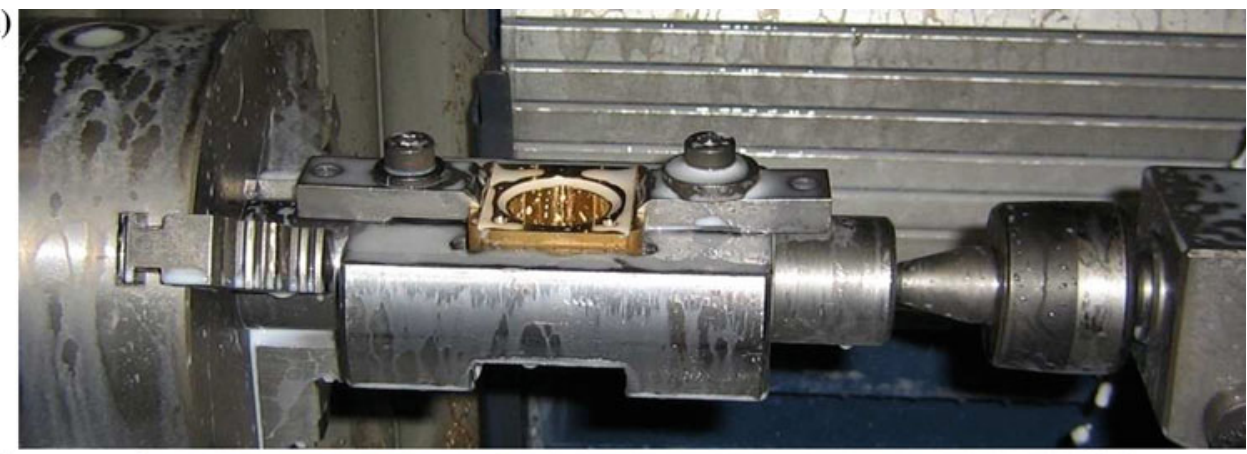

(b)

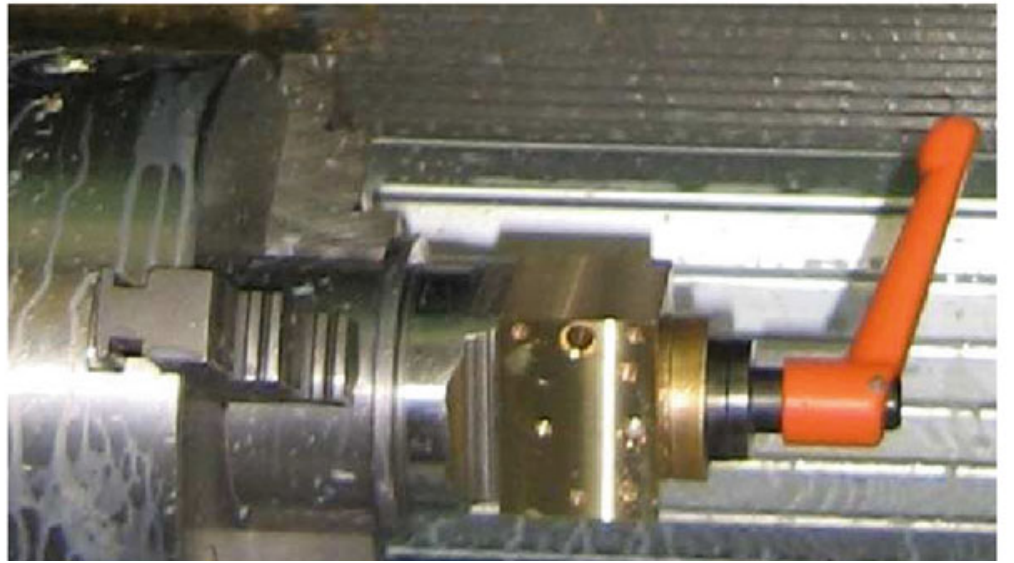

Fig. 4 Part setup solutions considered in machining process on vertical-spindle milling centre: a fixturing part for machining of datum (axial) hole, $\mathbf{b}$ holding part on a mandrel placed inside the datum hole for machining side planes and secondary surfaces

manufacturing (Fig. 5). Ten systems, and namely $\mathrm{S} 1 \div \mathrm{S} 10$, appropriate for machining individual features of the sample work piece are shown in Table 2. As seen, the process capabilities are given in the form of incidence relations of those machining systems and the discerned features $\mathrm{F} 1 \div \mathrm{F} 20$

Constraints matrix (Fig. 6) for available machining systems of the illustrative case study shows that some of them can not be applied from the beginning of the manufacturing process. S2 and S4 must be preceded by $\mathrm{S} 1$ or S3, and S8 by S7, respectively. The reason for that is illustrated in Fig. 4 where holding a part on a mandrel refers to the fixture type \# Fx2. The use of a mandrel requires a datum hole (feature F10) which is machined with the fixturing type \# Fx1 on a four axis CNC controlled vertical spindle milling machine (axes: $\mathrm{X}, \mathrm{Y}, \mathrm{Z}$ and $\mathrm{A}$ ). The same technological requirement is due to be met with reference to machining system S8, in which multi-piece fixturing is assumed.

The generation of the process plan network is consequently based on the FPM, PCM and CM matrices. Generated individual setups and entire manufacturing process alternatives included in the network subject to comparative assessment in terms of time using the MTM and STM matrices. Hence, with reference to the developed numerical case, the related values of manufacturing time components have

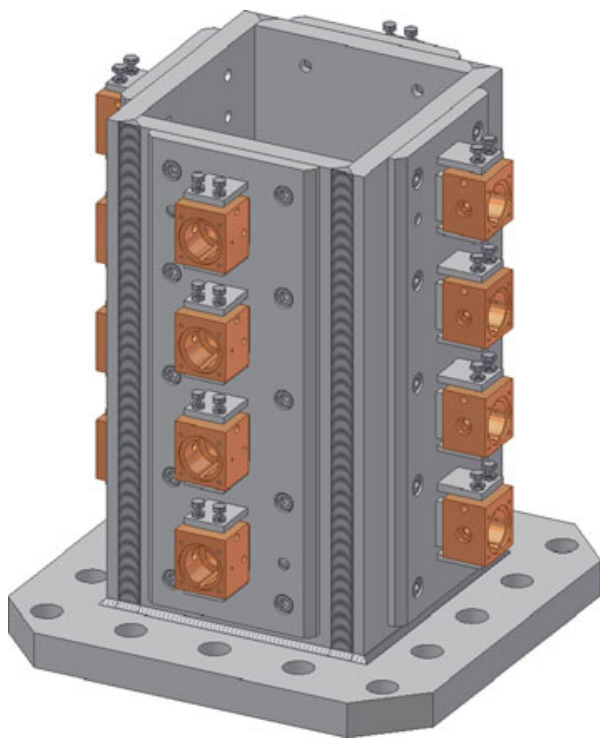

Fig. 5 Fixturing parts in a tower-type pallet applied to multi-part machining on a horizontal-spindle milling centre

been derived from the data base of the above mentioned real manufacturing plant.

The detailed procedure of proposed algorithm is presented numerically in Appendix A. It starts with the stock state and focuses on the consideration of only features that can be 
Table 2 Processing alternatives (capabilities) in the relation to individual features of the sample part

Machining system (machine \#/fixture \#) Feature

\begin{tabular}{|c|c|c|c|c|c|c|c|c|c|c|c|c|c|c|c|c|c|c|c|c|}
\hline & $\mathrm{F} 1$ & $\mathrm{~F} 2$ & F3 & F4 & F5 & F6 & F7 & F8 & F9 & F10 & F11 & F12 & F13 & F14 & F15 & F16 & F17 & F18 & F19 & $\mathrm{F} 20$ \\
\hline $\mathrm{S} 1$ (M1/Fx1) & $\mathrm{x}$ & $\mathrm{x}$ & $\mathrm{x}$ & $\mathrm{x}$ & $\mathrm{x}$ & $\mathrm{x}$ & $\mathrm{x}$ & $\mathrm{x}$ & $\mathrm{x}$ & $\mathrm{x}$ & $\mathrm{x}$ & $\mathrm{x}$ & $\mathrm{x}$ & & & & & & & \\
\hline S2 (M2/Fx2) & & & & & & & & & & & & & & $\mathrm{x}$ & $\mathrm{x}$ & $\mathrm{x}$ & $\mathrm{x}$ & $\mathrm{x}$ & $\mathrm{x}$ & $\mathrm{x}$ \\
\hline S3 (M3/Fx1) & $\mathrm{x}$ & $\mathrm{x}$ & $\mathrm{x}$ & $\mathrm{x}$ & $\mathrm{x}$ & $\mathrm{x}$ & $\mathrm{x}$ & $\mathrm{x}$ & $\mathrm{x}$ & $\mathrm{x}$ & $\mathrm{x}$ & $\mathrm{x}$ & $\mathrm{x}$ & & & & & & & \\
\hline S4 (M4/Fx2) & & & & & & & & & & & & & & $\mathrm{x}$ & $\mathrm{x}$ & $\mathrm{x}$ & $\mathrm{x}$ & $\mathrm{x}$ & $\mathrm{x}$ & $\mathrm{x}$ \\
\hline S5 (M5/Fx3) & $\mathrm{x}$ & & $\mathrm{x}$ & $\mathrm{x}$ & $\mathrm{x}$ & $\mathrm{x}$ & $\mathrm{x}$ & $\mathrm{x}$ & $\mathrm{x}$ & $\mathrm{x}$ & $\mathrm{x}$ & $\mathrm{x}$ & $\mathrm{x}$ & $\mathrm{x}$ & $\mathrm{x}$ & $\mathrm{x}$ & $\mathrm{x}$ & $\mathrm{x}$ & $\mathrm{x}$ & $\mathrm{x}$ \\
\hline S6 (M5/Fx4) & & $\mathrm{x}$ & & & & & & & & & & & & & & & & & & \\
\hline $\mathrm{S} 7(\mathrm{M} 1 / \mathrm{Fx} 5)^{*}$ & $\mathrm{x}$ & $\mathrm{x}$ & $\mathrm{x}$ & $\mathrm{x}$ & $\mathrm{x}$ & $\mathrm{x}$ & $\mathrm{x}$ & $\mathrm{x}$ & $\mathrm{x}$ & $\mathrm{x}$ & $\mathrm{x}$ & $\mathrm{x}$ & $\mathrm{x}$ & & & & & & & \\
\hline S8 (M2/Fx6)* & & & & & & & & & & & & & & $\mathrm{x}$ & $\mathrm{x}$ & $\mathrm{x}$ & $\mathrm{x}$ & $\mathrm{x}$ & $\mathrm{x}$ & $\mathrm{x}$ \\
\hline $\mathrm{S} 9(\mathrm{M} 5 / \mathrm{Fx} 7)^{* *}$ & $\mathrm{x}$ & & $\mathrm{x}$ & $\mathrm{x}$ & $\mathrm{x}$ & $\mathrm{x}$ & $\mathrm{x}$ & $\mathrm{x}$ & $\mathrm{x}$ & $\mathrm{x}$ & $\mathrm{x}$ & $\mathrm{x}$ & $\mathrm{x}$ & $\mathrm{x}$ & $\mathrm{x}$ & $\mathrm{x}$ & $\mathrm{x}$ & $\mathrm{x}$ & $\mathrm{x}$ & $\mathrm{x}$ \\
\hline S10 (M5/Fx8)** & & $\mathrm{x}$ & & & & & & & & & & & & & & & & & & \\
\hline
\end{tabular}

* Multi-piece machining process with 4 pieces in a pallet, ** with 16 pieces in a pallet

$\mathbf{C M}=\left[\begin{array}{cccccccccc}\text { S1 } & \text { S2 } & \text { S3 } & \text { S4 } & \text { S5 } & \text { S6 } & \text { S7 } & \text { S8 } & \text { S9 } & \text { S10 } \\ 0 & 1 & 0 & 1 & 0 & 0 & 0 & 7 & 0 & 0 \\ -1 & 3 & -1 & 3 & -1 & -1 & -1 & -1 & -1 & -1\end{array}\right]$

Fig. 6 Constraints matrix for available machining systems of the illustrative case study

machined at the very beginning of the process, which are further called as the initial features. The features F1, F2, F14, F15, identified here as initial features, can be carried out by 7 alternatives at this stage-Fig. 7. Two machining systems are chosen (S5, S9), with maximum number of completed features: F1, F14, F15. Subsequent features are established by searching data matrices until the need for a new setup occurs. Machining times for respective alternatives are next calculated by the formula (1), as shown in Table 1. Consequently, the alternative with machining system $\mathrm{S} 9$ is chosen due to the shorter machining time as compared with S5. The only missing feature F2 with possible machining systems $\mathrm{S} 1, \mathrm{~S} 3, \mathrm{~S} 6, \mathrm{~S} 7, \mathrm{~S} 10$ can be realised in five alternatives in a new setup and the alternative F2-S10 is selected as the shortest one. The total manufacturing time calculated (accordingly to the formula (2), as given in Table 1) for all features with chosen alternatives is set at this point as a commencing benchmark value. The whole procedure is repeated from the beginning for the two features: F1, F2 machined by three alternative routings with $\mathrm{S} 1, \mathrm{~S} 3$, and $\mathrm{S} 7$. After the setup completion, the machining system $\mathrm{S} 1$ is chosen as the one with the

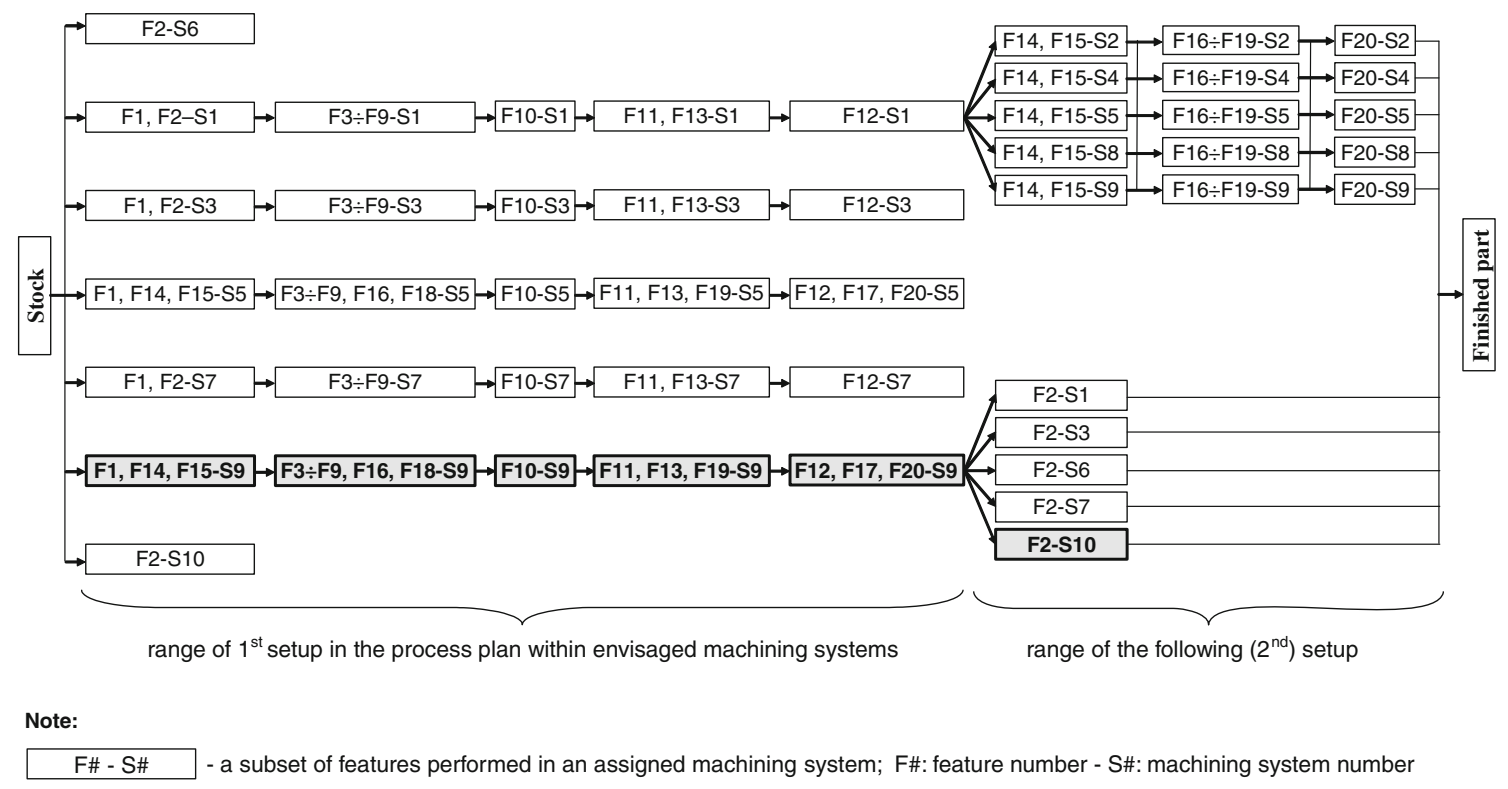

Fig. 7 The segment of process plan network with the optimal design solution marked with shaded boxes 


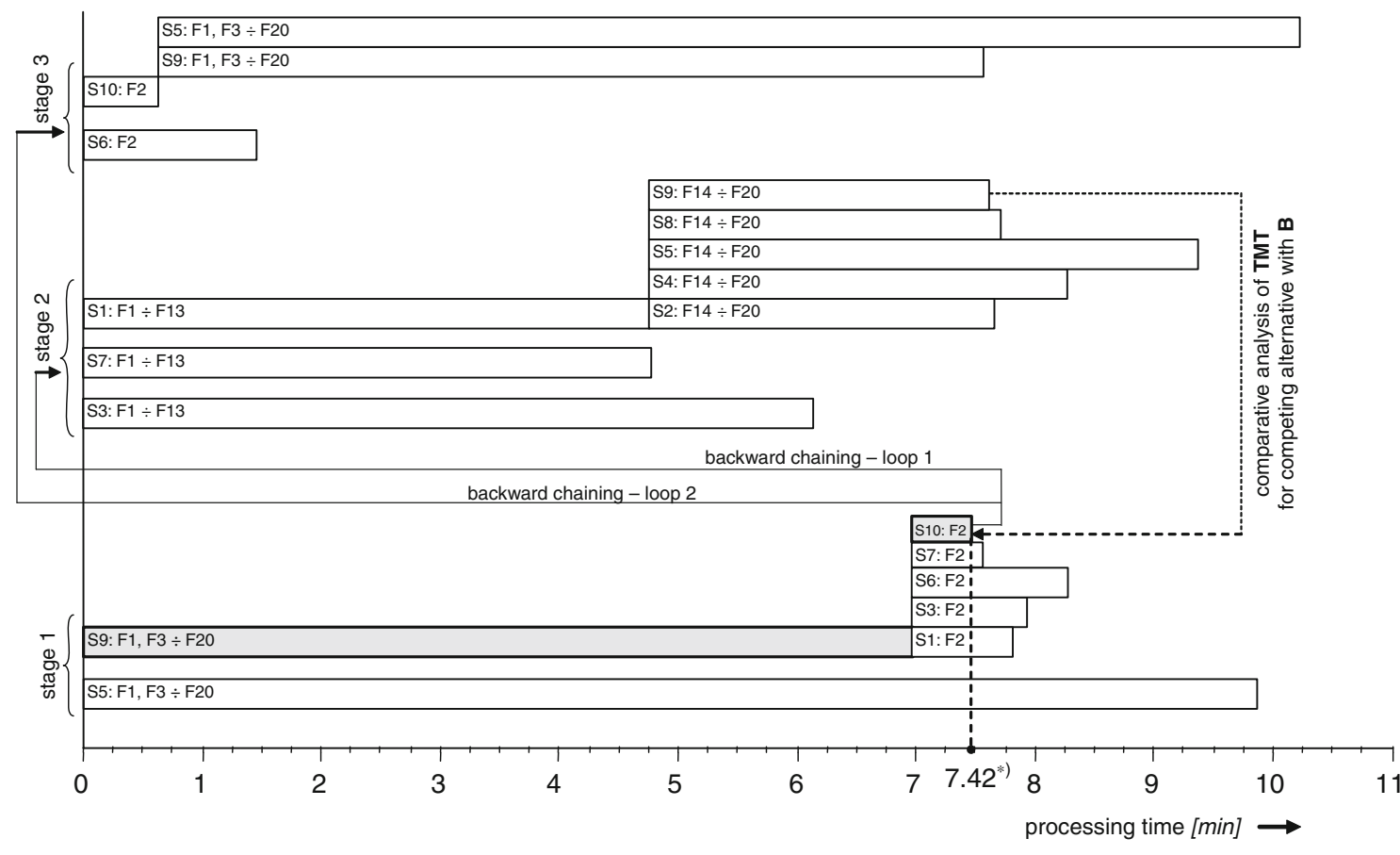

$\left.{ }^{*}\right) \mathrm{B}=$ TMT for the winning process alternative; where: $\mathrm{B}$ - current benchmark value, TMT - total machining time

Fig. 8 Decision making course for the identification of optimal machining process alternative (the winning process solution shown with shaded boxes)

shortest value of machining time which is compared with the benchmark. As its value is lower than the benchmark value, other remaining features are analysed in a new setup with five alternatives-S2, S4, S5, S8, S9 for features F14 and F15. After inclusion of all subsequent features in a branch, the setup with S9 machining system is found as the shortest one. The total machining time for the alternative branches carried out in S1 and S9 machining systems is calculated and compared with the benchmark. The winner alternative still remains the one within the branch S9-S10. There are two more alternatives at the first stage of the process plan network: F2-S6 and F2-S10. The branch F2-S10 as a shorter alternative can be expanded further with the use of S9 or S5 systems. The routing S10-S9 is similar to the one with S9S10, but with the lower number of features machined at the initial stage. Any sequence from the stock to the finished part state represents a valid alternative process plan. Taking into account the objective function value as the minimum total machining time, the optimal process plan solution involves the use of S9-S10 systems.

As a supplement to Fig. 7, the mechanism for decision making is presented in more descriptive manner in Fig. 8. It particularly reflects the order of the setups (machining systems) selection in machining process design. Decision process takes into account both forward and backward reasoning loops. Operations related to chosen setups are compared in terms of processing time that is measured along the abscissa.

\section{Conclusions}

Dynamic operation conditions of manufacturing facilities often cause process designs generated in advance to change even before their execution. There is a need to have a set of process plan alternatives at disposal to deal with uncertainty factors. Considering the above requirement, we propose a conceptual framework for the generation of process alternatives in the form of a network. A relevant hierarchical procedure is proposed for creating such a network and extracting optimal process plan solutions from the viewpoint of their operational performance. The system utilises matrix recording of input data sets, which comprise: feature-based product data model, machining systems capabilities and process constraints. The matrix formulation of machining process constraints is a unique method proposed by authors, effectively used by developed algorithm for feature clustering into consecutive setups. The usability of the approach is studied numerically with regard to a real life case study of a complex prismatic part machined with the use of multi-axis centres, and equipped with relevant fixtures, as far as the conditions of multiple piece machining are concerned. The proposed system is principally appropriated for prismatic parts, however, it can be also successfully applied to rotational part components. The experimental results reveal its capability of identifying the most effective machining process design, considering actual 
production conditions with regard to the constraints of a fixturing strategy, and the availability of a specific tool set.

Our contributions beside the reported work in the literature can be recapitulated as follows: (1) the unique matrix coding of part data in terms of features and manufacturing constrains enables the selection of effective and efficient setups and process plans, where machine availability and capability change over time. Owing to such a meaningful form of data representation a set of adequate process solutions can be timely generated in an automated manner. (2) Constraints of manufacturing resources (machine tools and equipment) are considered explicitly at the setup formulation stage for the network of alternative processes, including those of multiple piece machining. (3) Application of the proposed reasoning scheme and relevant algorithm yield optimal process plan designs from the viewpoint of time/cost and machine utilisation criteria.

Our further research aims at the extension of the proposed modelling scheme by sets of technological data, as implied in enriched machining features (EMFs)-based reasoning approach. It could be contributive to automated selection of tools, cutting parameters as well as time standards. Thus, process planning could be further integrated with scheduling tasks.

Acknowledgments Authors would like to thank the management board of the manufacturing plant SIM Gdynia (http://www.simgdynia. eu) for providing relevant data used in the research. Computations carried out with the use of software and computers from Academic Computer Centre in Gdansk-TASK (http://www.task.gda.pl).

Open Access This article is distributed under the terms of the Creative Commons Attribution License which permits any use, distribution, and reproduction in any medium, provided the original author(s) and the source are credited.

\section{Appendix A}

The following calculations with the elements of pseudocode, describe steps of the developed algorithm presented in Table 1, using numerical data related to the illustrative case. It shows in detail a numerical realisation of the developed algorithm.

\section{Step \# 1:}

$$
\begin{aligned}
& \begin{array}{lllllll}
\mathrm{j}=1 & 2 \\
\downarrow & \downarrow & 14 & \downarrow & 15
\end{array}
\end{aligned}
$$

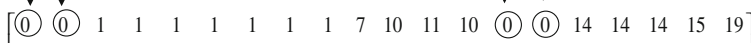

$$
\begin{aligned}
& F P M=\left[\begin{array}{llllllllllllllllllllll}
-1 & -1 & -1 & -1 & -1 & -1 & -1 & -1 & -1 & 8 & -1 & -1 & -1 & -1 & -1 & -1 & 11 & -1 & 10 & -1
\end{array}\right] \\
& {\left[\begin{array}{llllllllllllllllllllll}
-1 & -1 & -1 & -1 & -1 & -1 & -1 & -1 & -1 & 9 & -1 & -1 & -1 & -1 & -1 & -1 & -1 & -1 & -1 & -1
\end{array}\right]} \\
& J_{s}=\left[\begin{array}{llll}
1 & 2 & 14 & 15
\end{array}\right], J_{q}=\left[\begin{array}{llll}
1 & 2 & 14 & 15
\end{array}\right]
\end{aligned}
$$

Step \# 2:

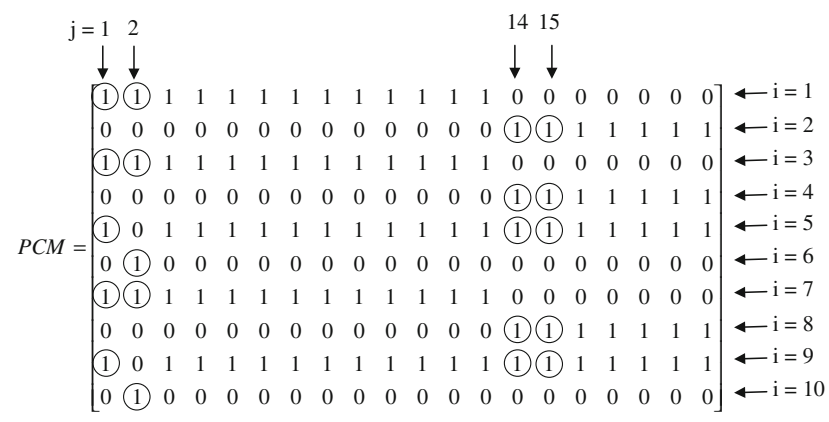

$I_{r}=\left[\begin{array}{llllllllll}1 & 2 & 3 & 4 & 5 & 6 & 7 & 8 & 9 & 10\end{array}\right]$

Step \# 3:

$C M=\left[\begin{array}{ccccccccccc}\mathrm{j}=1 & & 3 & & 5 & 6 & 7 & & 9 & 10 \\ 0 & 1 & 0 & 1 & 0 & 0 & 0 & 7 & 0 & 0 \\ -1 & 3 & -1 & 3 & -1 & -1 & -1 & -1 & -1 & -1\end{array}\right]$

$J_{r}=\left[\begin{array}{lllllll}1 & 3 & 5 & 6 & 7 & 9 & 10\end{array}\right]$

\section{Step \# 4:}

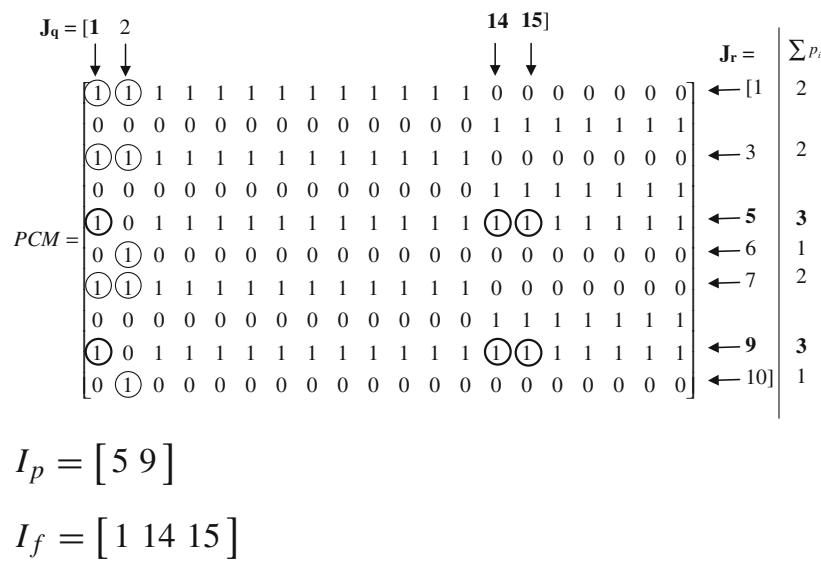

\section{Step \# 5:}

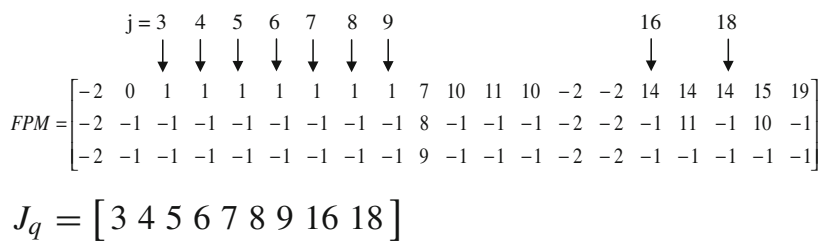




\section{Step \# 6:}

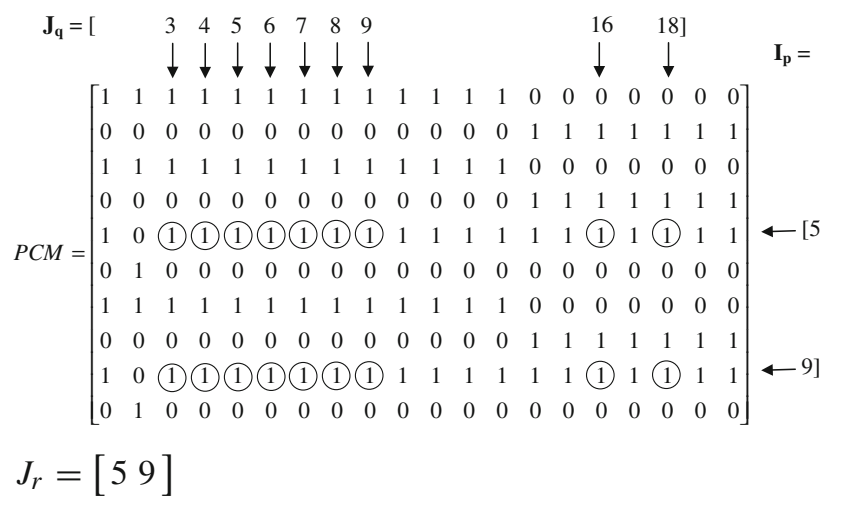

\section{Step \# 7:}

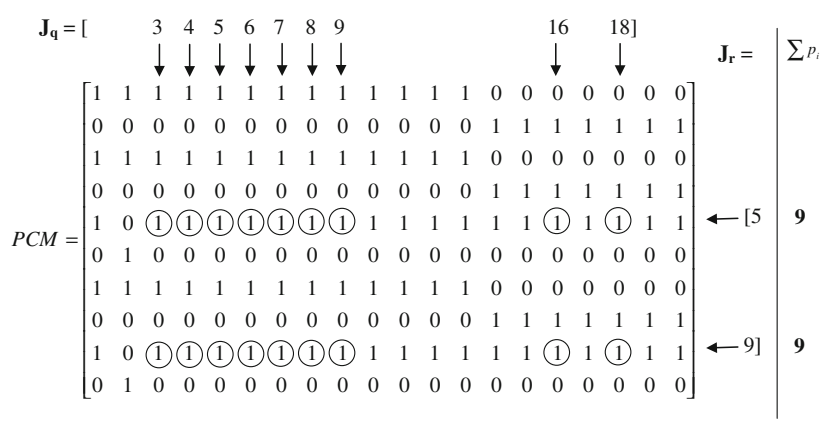

$$
\begin{aligned}
& I_{p}=\left[\begin{array}{ll}
5 & 9
\end{array}\right]
\end{aligned}
$$

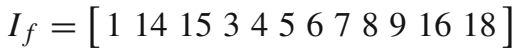

\section{Step \# 8:}

\section{Go to Step 5}

\section{Step\#5; iteration\#1 :}

$$
\begin{aligned}
& F P M=\left[\begin{array}{llllllllllllllllllll}
-2 & 0 & -2 & -2 & -2 & -2 & -2 & -2 & -2 & 7 & 10 & 11 & 10 & -2 & -2 & -2 & 14 & -2 & 15 & 19 \\
-2 & -1 & -2 & -2 & -2 & -2 & -2 & -2 & -2 & 8 & -1 & -1 & -1 & -2 & -2 & -2 & 11 & -2 & 10 & -1 \\
-2 & -1 & -2 & -2 & -2 & -2 & -2 & -2 & -2 & 9 & -1 & -1 & -1 & -2 & -2 & -2 & -1 & -2 & -1 & -1
\end{array}\right] \\
& J_{q}=[10]
\end{aligned}
$$

\section{Step \# 6; iteration \#1:}

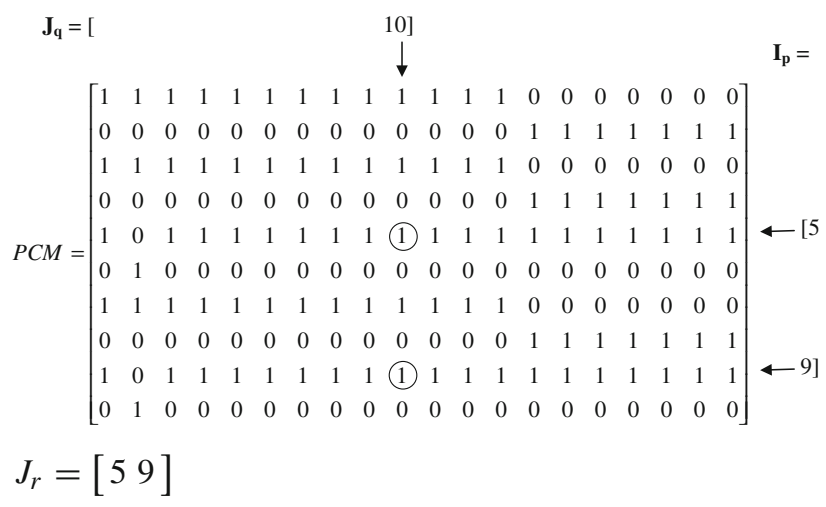

Step \# 7; iteration \#1:

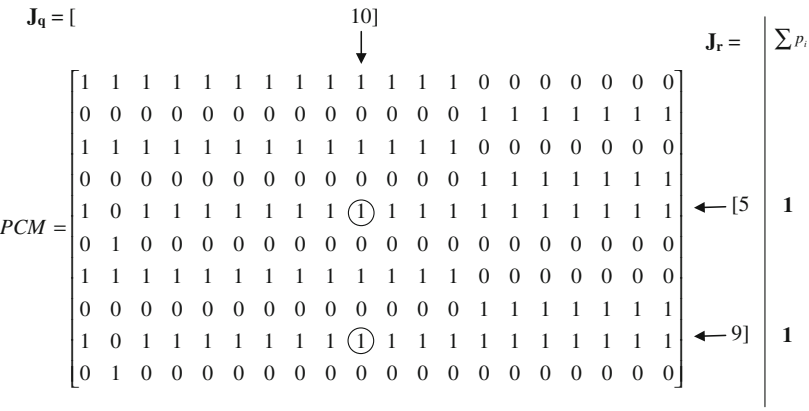

$$
\begin{aligned}
& I_{p}=\left[\begin{array}{ll}
5 & 9
\end{array}\right]
\end{aligned}
$$

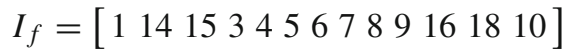

\section{Step \# 8; iteration \#1:}

Go to Step 5

Step \# 5; iteration \#2:

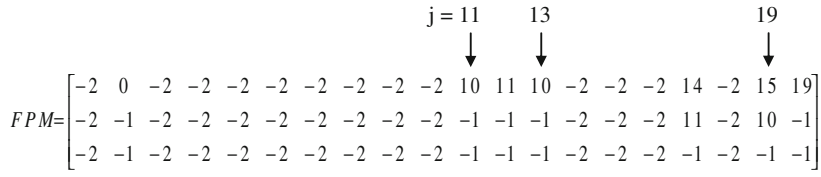

$$
\begin{aligned}
& J_{q}=\left[\begin{array}{lll}
11 & 13 & 19
\end{array}\right]
\end{aligned}
$$

Step \# 6; iteration \#2:

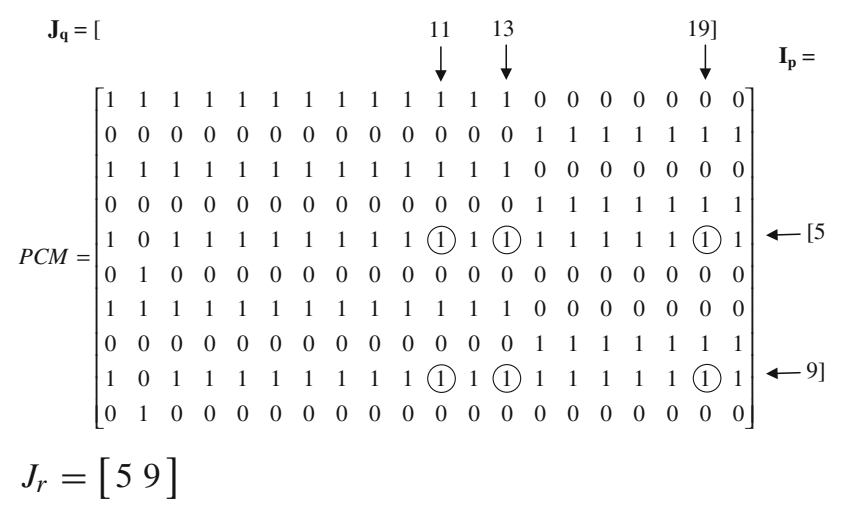

\section{Step \# 7; iteration \#2:}

$$
\begin{aligned}
& \mathbf{J}_{\mathbf{q}}=[ \\
& {\left[\begin{array}{llllllllllllllllllll}
1 & 1 & 1 & 1 & 1 & 1 & 1 & 1 & 1 & 1 & 1 & 1 & 1 & 0 & 0 & 0 & 0 & 0 & 0 & 0
\end{array}\right]} \\
& \begin{array}{llllllllllllllllllll}
0 & 0 & 0 & 0 & 0 & 0 & 0 & 0 & 0 & 0 & 0 & 0 & 0 & 1 & 1 & 1 & 1 & 1 & 1 & 1
\end{array} \\
& \begin{array}{llllllllllllllllllll}
1 & 1 & 1 & 1 & 1 & 1 & 1 & 1 & 1 & 1 & 1 & 1 & 1 & 0 & 0 & 0 & 0 & 0 & 0 & 0
\end{array}
\end{aligned}
$$

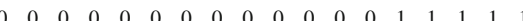

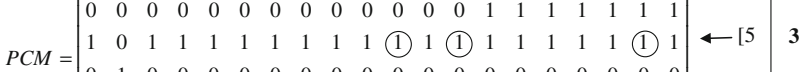

$$
\begin{aligned}
& =\begin{array}{llllllllllllllllllll}
0 & 1 & 0 & 0 & 0 & 0 & 0 & 0 & 0 & 0 & 0 & 0 & 0 & 0 & 0 & 0 & 0 & 0 & 0 & 0
\end{array} \\
& \begin{array}{llllllllllllllllllll}
1 & 1 & 1 & 1 & 1 & 1 & 1 & 1 & 1 & 1 & 1 & 1 & 1 & 0 & 0 & 0 & 0 & 0 & 0 & 0
\end{array} \\
& \begin{array}{llllllllllllllllllll}
0 & 0 & 0 & 0 & 0 & 0 & 0 & 0 & 0 & 0 & 0 & 0 & 0 & 1 & 1 & 1 & 1 & 1 & 1 & 1
\end{array} \\
& \left.\begin{array}{llllllllllllllllllll}
1 & 0 & 1 & 1 & 1 & 1 & 1 & 1 & 1 & 1 & (1) & 1 & (1) & 1 & 1 & 1 & 1 & 1 & (1) & 1 \\
0 & 1 & 0 & 0 & 0 & 0 & 0 & 0 & 0 & 0 & -9
\end{array}\right] \mathbf{3} \\
& I_{p}=\left[\begin{array}{ll}
5 & 9
\end{array}\right]
\end{aligned}
$$

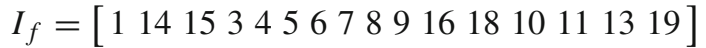




\section{Step \# 8; iteration \#2:}

Go to Step 5

Step \# 5; iteration \#3:

$F P M=\left[\begin{array}{cccccccccccccccccccc}-2 & 0 & -2 & -2 & -2 & -2 & -2 & -2 & -2 & -2 & -2 & 11 & -2 & -2 & -2 & -2 & 14 & -2 & -2 & 19 \\ -2 & -1 & -2 & -2 & -2 & -2 & -2 & -2 & -2 & -2 & -2 & -1 & -2 & -2 & -2 & -2 & 11 & -2 & -2 & -1 \\ -2 & -1 & -2 & -2 & -2 & -2 & -2 & -2 & -2 & -2 & -2 & -1 & -2 & -2 & -2 & -2 & -1 & -2 & -2 & -1\end{array}\right]$

$J_{q}=\left[\begin{array}{lll}12 & 17 & 20\end{array}\right]$

Step \# 6; iteration \#3:

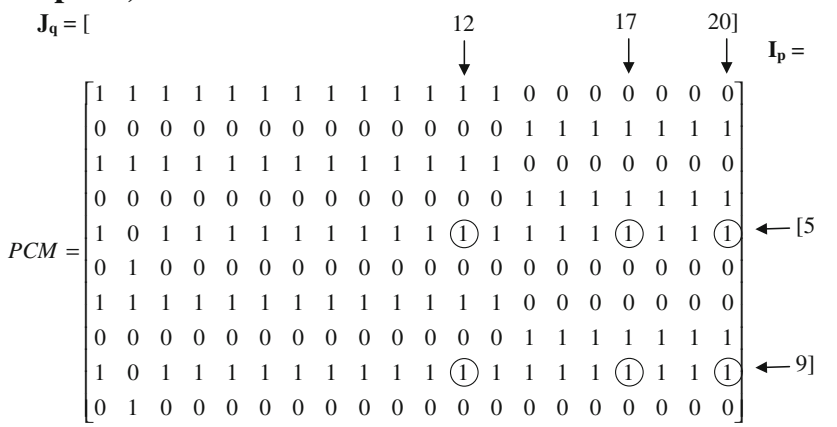

$J_{r}=\left[\begin{array}{ll}5 & 9\end{array}\right]$

Step \# 7; iteration \#3:

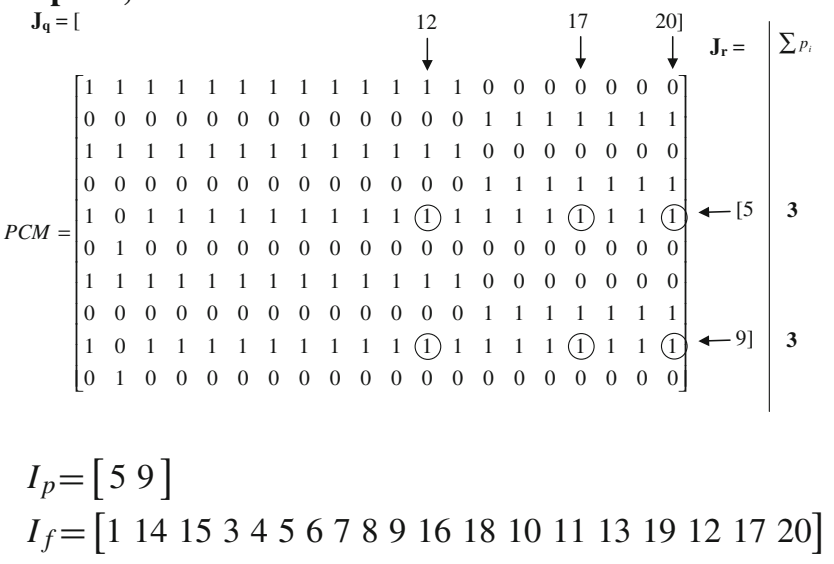

\section{Step \# 8; iteration \#3:}

Go to Step 5

Step \# 5; iteration \#4:

$$
\begin{aligned}
& \text { no } j \text { elements }
\end{aligned}
$$

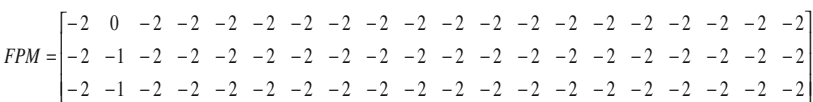

$$
\begin{aligned}
& J_{q}=[]-\text { go to Step } 9
\end{aligned}
$$

\section{Step \# 9:}

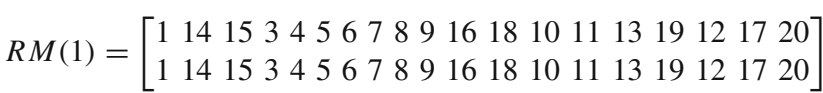

Using the formula (1), given in Table 1, for calculations,

\section{begin the procedure:}

$\max \left(\operatorname{size}\left(\mathrm{I}_{\mathrm{p}}\right)\right)=2$

$\mathrm{p}=1$-corresponds to the first row of $\mathbf{R M}$; features listed in rows of $\mathbf{R M}$ may differ.

$$
\begin{aligned}
& \quad E M T_{1}(1,5)=t_{5,1}+t_{5,14}+t_{5,15}+\cdots+t_{5,20}+s_{5}= \\
& \quad 9.79 \min \\
& \mathrm{p}=2 \\
& \quad E M T_{1}(2,9)=t_{9,1}+t_{9,14}+t_{9,15}+\cdots+t_{9,20}+s_{9}= \\
& \quad 6.95 \min
\end{aligned}
$$

end

$\min \left(\mathrm{EMT}_{1}\right)=6.95 \mathrm{~min} ; \mathrm{S} 9$ selected of S5 and S9 systems. Step \# 10:

Since chosen system \#9 is not required by other systems (as noted in $\mathrm{CM}$ ), thus:

$I_{p}^{*}=[]$

initial value of $B=100 \mathrm{~min}$

$\mathrm{SMT}_{1}=\mathrm{EMT}_{1}=6.95$ min; continue, as $\mathrm{SMT}_{1}<\mathrm{B}$

\section{Step \# 11:}

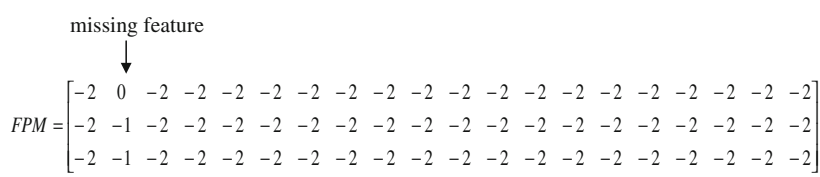

\section{go to Step 1}

Step \# 1; Setup \#2:

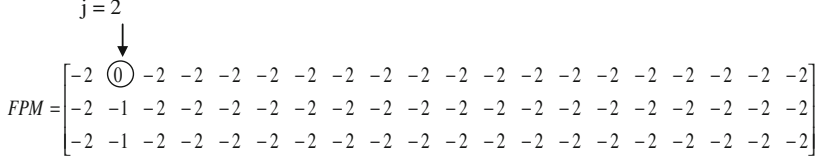

$$
\begin{aligned}
& J_{s}=[2], J_{q}=[2]
\end{aligned}
$$

\section{Step \# 2; Setup \#2:}

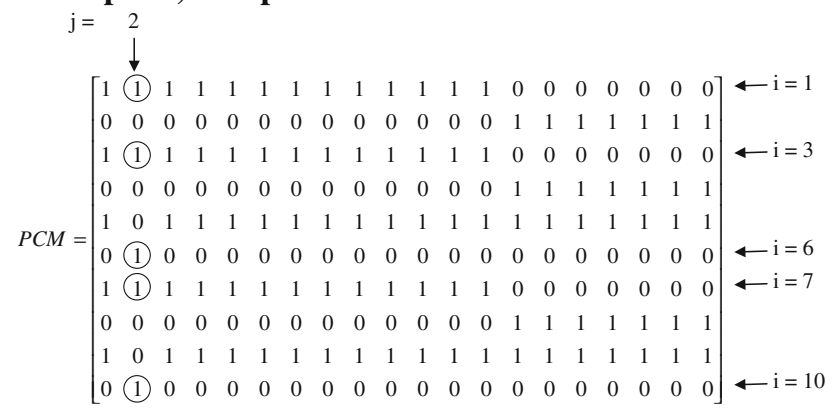

$I_{r}=\left[\begin{array}{lllll}1 & 3 & 6 & 7 & 10\end{array}\right]$ 
Step \# 3; Setup \#2:

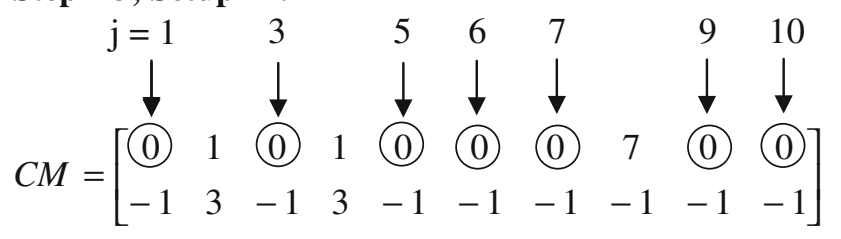

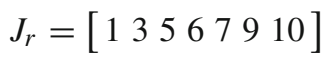

Step \# 4; Setup \#2:

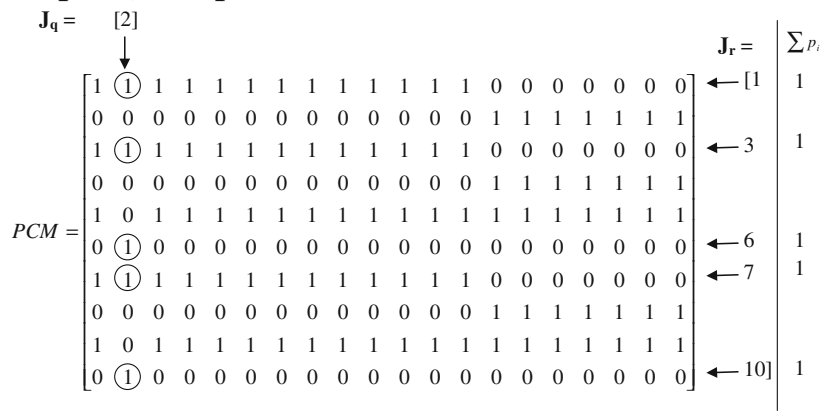

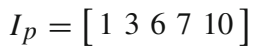

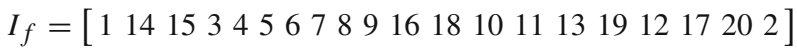

\section{Step \# 5; Setup \#2:}

no $j$ elements

$F P M=\left[\begin{array}{llllllllllllllllllll}-2 & -2 & -2 & -2 & -2 & -2 & -2 & -2 & -2 & -2 & -2 & -2 & -2 & -2 & -2 & -2 & -2 & -2 & -2 & -2 \\ -2 & -2 & -2 & -2 & -2 & -2 & -2 & -2 & -2 & -2 & -2 & -2 & -2 & -2 & -2 & -2 & -2 & -2 & -2 & -2 \\ -2 & -2 & -2 & -2 & -2 & -2 & -2 & -2 & -2 & -2 & -2 & -2 & -2 & -2 & -2 & -2 & -2 & -2 & -2 & -2\end{array}\right]$

$J_{q}=[]$-go to Step 9

Step \# 9:

$R M(2)=\left[\begin{array}{l}2 \\ 2 \\ 2 \\ 2 \\ 2\end{array}\right]$

Using the formula (1)—see Table 1, for calculations,

begin the procedure:

$\max \left(\operatorname{size}\left(\mathrm{I}_{\mathrm{p}}\right)\right)=5$

$\mathrm{p}=1$-corresponds to the first row of $\mathbf{R M}$ (features listed in rows of $\mathbf{R M}$ may differ).

$$
\begin{aligned}
& E M T_{2}(1,1)=t_{1,2}+s_{1}=0.79 \mathrm{~min} \\
& \mathrm{p}=2 \\
& E M T_{2}(2,3)=t_{3,2}+s_{3}=0.84 \mathrm{~min} \\
& \mathrm{p}=3 \\
& E M T_{2}(3,6)=t_{6,2}+s_{6}=1.27 \mathrm{~min} \\
& \mathrm{p}=4 \\
& E M T_{2}(4,7)=t_{7,2}+s_{7}=0.62 \mathrm{~min} \\
& \mathrm{p}=5 \\
& E M T_{2}(5,10)=t_{10,2}+s_{10}=0.47 \mathrm{~min}
\end{aligned}
$$

end

$\min \left(\mathrm{EMT}_{2}\right)=0.47 \mathrm{~min} ; \mathrm{S} 10$ selected of S1, S3, S6, S7 and S10 machining systems.

\section{Step \# 10:}

Chosen system \#10 is not required by other systems (as noted in $\mathrm{CM}$ ), hence:

$\mathbf{I}_{p}^{*}=[]$

Accordingly to the formula (2):

$\mathrm{SMT}_{1}=\mathrm{EMT}_{1}+\mathrm{EMT}_{2}=7.42$ min; continue, as $\mathrm{SMT}_{1}<\mathrm{B}$; $(\mathrm{B}=100 \mathrm{~min})$

\section{Step \# 11:}

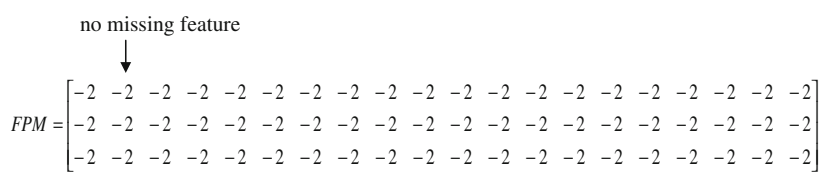

Step \# 12:

$\mathrm{TMT}_{1}=\mathrm{SMT}_{1}=7.42 \mathrm{~min}$

Step \# 13:

A new benchmark $B=7.42$ min

Step \# 14:

Go to Step 4 to consider the reminder of matching possibilities.

Step \# 4:

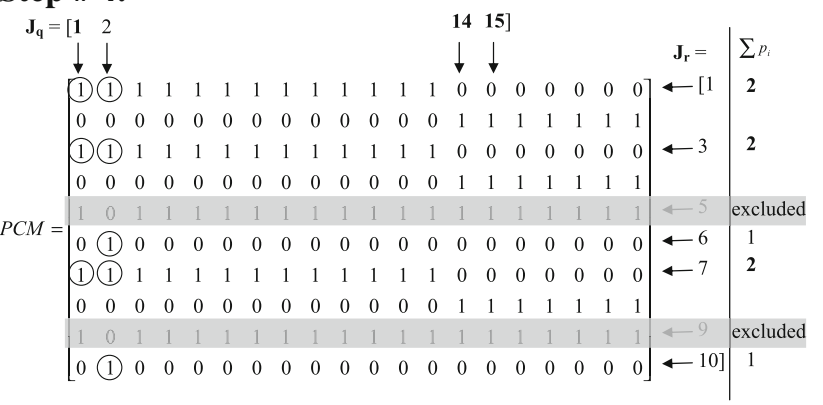

$I_{p}=\left[\begin{array}{lll}1 & 3 & 7\end{array}\right]$

$I_{f}=\left[\begin{array}{ll}1 & 2\end{array}\right]$

Continue according to the algorithm (see Table 1).

\section{References}

Chung, D.-H., \& Suh, S.-H. (2008). ISO 14649-based nonlinear process planning implementation for complex machining. Computer-Aided Design, 40, 521-536.

Gao, J., Zheng, D. T., \& Gindy, N. (2004). Extraction of machining features for CAD/CAM integration. International Journal of Advanced Manufacturing Technology, 24, 573-581.

Gologlu, C. (2004). Machine capability and fixturing constraintsimposed automatic machining set-ups generation. Journal of Materials Processing Technology, 148, 83-92.

Hayasi, M. T., \& Asiabanpour, B. (2009). Extraction of manufacturing information from design-by-feature solid model through feature recognition. International Journal of Advanced Manufacturing Technology, 44, 1191-1203.

Kang, M., Han, J., \& Moon, J. G. (2003). An approach for interlinking design and process planning. Journal of Materials Processing Technology, 139, 589-595. 
Lee, H. C., Jhee, W. C., \& Park, H.-S. (2007). Generative CAPP through projective feature recognition. Computers \& Industrial Engineering, 53, 241-246.

Liu, Z., \& Wang, L. (2007). Sequencing of interacting prismatic machining features for process planning. Computers in Industry, 58, 295-303.

Mokhtar, A., \& Xu, X. (2011). Machining precedence of 2 1/2 D interacting features in a feature-based data model. Journal of Intelligent Manufacturing, 22(2), 145-161.

Mokhtar, A., Xu, X., \& Lazcanotegui, I. (2009). Dealing with feature interactions for prismatic parts in STEP-NC. Journal of Intelligent Manufacturing, 20(4), 431-445.

Molina, A., Rodriguez, C. A., Ahuett, H., Cortes, J. A., Ramirez, M., Jimenez, G., \& Martinez, S. (2005). Next-generation manufacturing systems: Key research issues in developing and integrating reconfigurable and intelligent machines. International Journal of Computer Integrated Manufacturing, 18(7), 525-536.

Park, S. C. (2003). Knowledge capturing methodology in process planning. Computer-Aided Design, 35, 1109-1117.

Raman, R., \& Marefat, M. M. (2004). Integrated process planning using tool/process capabilities and heuristic search. Journal of Intelligent Manufacturing, 15, 141-174.

Rameshbabu, V., \& Shunmugam, M. S. (2009). Hybrid feature recognition method for setup planning from STEP AP-203. Robotics and Computer-Integrated Manufacturing, 25, 393-408.

Sormaz, D. N., \& Khoshnevis, B. (2000). Modeling of manufacturing feature interactions for automated process planning. Journal of Manufacturing Systems, 19(1), 28-45.

Sormaz, D. N., \& Khoshnevis, B. (2003). Generation of alternative process plans in integrated manufacturing systems. Journal of Intelligent Manufacturing, 14(5), 509-526.

Srinivasan, M., \& Sheng, P. (1999). Feature based process planning in environmentally conscious machining-Part 2: Macroplan- ning. Robotics and Computer-Integrated Manufacturing, 15, 271281.

Tanaka, F., \& Kishinami, T. (1998). Geometrical characteristics of machined shape for computer aided operation planning. Journal of Materials Processing Technology, 76, 109-114.

Wang, L., Cai, N., Feng, H.-Y., \& Liu, Z. (2006). Enriched machining feature based reasoning for generic machining process sequencing. International Journal of Production Research, 44(8), 14791501.

Wang, L., Cai, N., Feng, H.-Y., \& Ma, J. (2010). ASP: An adaptive setup planning approach for dynamic machine assignments. IEEE Transactions on Automation Science and Engineering, 7(1), 2-14.

Wang, L., \& Shen, W. (2003). DPP: An agent-based approach for distributed process planning. Journal of Intelligent Manufacturing, 14(5), 429-439.

Wong, T. N., Chan, L. C. F., \& Lau, H. C. W. (2003). Machining process sequencing with fuzzy expert system and genetic algorithms. Engineering with Computers, 19, 191-202.

Xu, X., Wang, L., \& Newman, S. T. (2011). Computer-aided process planning-A critical review of recent developments and future trends. International Journal of Computer Integrated Manufacturing, 24(1), 1-31.

Zhao, Y. F., Habeeb, S., \& Xu, X. (2009). Research into integrated design and manufacturing based on STEP. International Journal of Advanced Manufacturing Technology, 44, 606-624.

Zheng, L. Y., Dong, H. F., Vichare, P., Nassehi, A., \& Newman, S. T. (2008). Systematic modeling and reusing of process knowledge for rapid process configuration. Robotics and Computer-Integrated Manufacturing, 24, 763-772.

Zhou, X., Qiu, Y., Hua, G., Wang, H., \& Ruan, X. (2007). A feasible approach to the integration of CAD and CAPP. Computer-Aided Design, 39, 324-338. 